\title{
DE LOS ENAMORADOS, SON LOS MENOS LOS CASADOS. LA EXPRESIÓN DE LA VOLUNTAD PERSONAL DE LOS JÓVENES EN LAS RELACIONES PRENUPCIALES DE ANTIGUO RÉGIMEN
}

\author{
Elena Paoletti Ávila* \\ UNIVERSIDAD DE EXTREMADURA
}

\begin{abstract}
RESUMEN
María Gallego, natural de Hinojosa, declaró en 1775 que "para enamorar, el que mejor parezca y para casar, el que convenga". Diferenció así dos momentos en la vida de un joven: el del libre albedrío y el del sometimiento a las directrices familiares. El presente trabajo tiene por objeto el estudio de los jóvenes como protagonistas de la emergencia de la voluntad personal y acciones individualistas en prácticas en torno al noviazgo y acceso al matrimonio en el siglo XVIII. A través de tratados de familia, legislación de la época y pleitos eclesiásticos, analizamos el conflicto social y moral que deviene de la expresión de la voluntad personal de los jóvenes hijos de familia y la actuación de los poderes político y religioso contra esas pulsaciones individualistas. Sin embargo, la generalización de pautas culturales derivadas de los idearios ilustrados dotará de mayor importancia al consentimiento personal y amparará la generalización de acciones individualistas, transformando los modos de vida sobre los que se expandirá la armadura ideológica, institucional y costumbres del liberalismo.
\end{abstract}

PALABRAS CLAVE: jóvenes, familia, voluntad individual, matrimonio, siglo XVIII

Enviado: 15-9-2019

Aceptado: 15-1-2020

*epaoletti@unex.es 


\title{
MARRIED PEOPLE ARE THE ONES WHO ARE IN LOVE THE LEAST. THE EXPRESSION OF YOUNG PEOPLE'S PERSONAL WILL IN THE PRE-MATRIMONIAL RELATIONSHIPS IN THE ANCIENT REGIME
}

\author{
Elena Paoletti Ávila* \\ UNIVERSIDAD DE EXTREMADURA
}

\begin{abstract}
María Gallego declared in 1775 that "to fall in love, the one that seems best and to marry, the one that suits". She differentiated two moments in the lives of young people: in one had the free will and in other hand the submission to family will. This paper studies the emergence of the personal will of young people in practices around dating and access to marriage in the eighteenth century. We analyze the social and moral conflict caused by the confrontation of the expression of the personal will of young people and the action of political and religious powers against these individualistic pulsations. The methodology uses family treaties, legislation of the time and ecclesiastical lawsuits. However, the increasing importance of personal consent in the illustrated ideals will support the generalization of individualistic actions. These individualistic actions will transform the ways of life over which liberalism will expand.
\end{abstract}

KEYWORDS: youth, family, individualistic will, marriage, 18th century 


\section{INTRODUCCIÓN}

Las relaciones prenupciales son un tema historiográfico que goza de una atención cada vez más intensa por parte de la comunidad de los modernistas españoles, no sólo desde el punto de vista de la historia social de la población, sino también a partir de visiones más complejas desde el punto de vista conceptual ${ }^{1}$. Una de ellas es la que asocia este acontecimiento del ciclo de vida con la juventud y sus manifestaciones. Pese a ello, subsisten numerosas lagunas.

Quizás la construcción de un relato que convierte la juventud en objeto de estudio histórico merezca un detenimiento que ahora no podemos desarrollar. Baste decir, sin embargo, que los jóvenes y la juventud ocupan un espacio progresivamente mayor en las publicaciones científicas, en especial en aquellas orientadas a la historia social de la población y de la cultura en la época moderna ${ }^{2}$. A pesar de lo cual, es evidente que algunos aspectos de

1. Este trabajo está financiado por la ayuda para la formación de profesorado universitario (FPU) 2016 y con fondos del proyecto de investigación HAR2013-48901-C6-5-R del MINECO y se incluye en los trabajos desarrollados dentro del Grupo para el Estudio de la Historia Social en el Occidente Moderno Peninsular (GEHSOMP), de la Junta de Extremadura. Es el resultado de la ponencia "Jóvenes e individualismo en el pensamiento ilustrado", presentada en el Simposio Entornos rurales de cambio. Familias, desmantelamiento de solidaridades y ruptura de jerarquias (ss. XVI-XX), organizado por los profesores Francisco Chacón Jiménez y Francisco García González, y celebrado en la Facultad de Humanidades de Albacete los días 9 y 10 de noviembre de 2017.

2. Destacan las obras de V. Alba (1975) con un tinte sociológico; desde un punto de vista más histórico contamos con los textos de S. Souto Kustrín (2007a), 171-192; (2007b) 1120; M. Mitterauer (1992) o, especialmente, la obra colectiva de G. LeVI y J.-C. Schmitt (1996). Recientemente contamos con dos nuevas obras; la de M. GARCíA Fernández (2019), que trata de definir "aquella edad de la discreción" a través del estudio de minorías de edad y tutorías y la obra colectiva de J. P. Blanco Carrasco, M. García Fernández y F. Olival (2019) que recoge una serie de trabajos que resumen las principales líneas de estudio de la juventud actuales, como son los marcos de civilización juvenil, el ciclo de vida, la problemática del cambio intergeneracional o la emergencia de la voluntad personal.

En concreto, en torno al relativamente reciente debate sobre la emergencia de la voluntad personal y la obediencia crítica en la juventud española de finales de la época moderna cabe destacar los trabajos que desde el 2014 se han venido desarrollando desde la Universidad de Extremadura, algunos de los cuales manejamos en esta bibliografía, tales como J. P. Blanco Carrasco (2016), 107-135, en el que el autor analiza las facetas de la patria potestad en el Antiguo Régimen para comprender el sistema de acuerdos y consensos con los que la sociedad moderna se regula internamente y el modo en el que irrumpe y comienza a imponerse una mentalidad distinta; (2019a), 323-345, centrado en los cambios sociales que están provocando ciertas innovaciones en el seno de las 
sus vidas resultan menos conocidos y requieren mayor atención. Precisamente con esa premisa queremos recalar con este estudio en un momento crítico en sus vidas, los umbrales del matrimonio, intentando descubrir qué márgenes de libertad tenían y en qué escenarios podemos situarlos.

Entre las organizaciones humanas, la familia es la que más interés ha concitado entre los historiadores como objeto social individuado en el Antiguo Régimen, que ayuda a comprender el funcionamiento de las comunidades en las que se inserta y que sirve de nexo de unión entre lo público y lo privado, entre el individuo y la sociedad. Dentro de la configuración de una familia, la vida en pareja ocupa un lugar sustancial como determinante no solo del modelo familiar o las estrategias de un grupo, sino también de la supervivencia y evolución de las comunidades. Ahora bien, ¿cuál es la mecánica de formación?

Aunque la producción científica es, afortunadamente, muy abundante ${ }^{3}$, el peso explicativo de las estrategias familiares ligadas a la constitución de los matrimonios ha generado una concepción rígida del proceso. Al mismo tiempo, ha ocultado otras posibilidades de estudio, como son las manifestaciones de la voluntad personal, que nos conducen a un pano-

familias y que tienen que ver con el conflicto intergeneracional que se da entre padres e hijos jóvenes. Esto es, la conexión entre una desobediencia crítica que afecta a los jóvenes hijos de familia y los nuevos marcos de referencia en los que se desenvuelven los distintos actores sociales; (2019b), 45-72, que continúa la línea del anterior trabajo, abundando más en el concepto de la desobediencia crítica, y la función de los jóvenes, la juventud regulada, en el seno de las familias modernas; E. Paoletti Ávila y J. P. Blanco CARRasco (2018), 393-406, en el que se analizan las prácticas coercitivas que las familias imponen a sus hijos en las prácticas matrimoniales y la progresiva ampliación de márgenes de libertad de los contrayentes conforme se van generalizando pautas culturales derivadas de los idearios de la Ilustración y el Liberalismo; E. Paolettr Ávila (2019), 345-361, centrado en el salto generacional que los emigrados cameranos, la mayoría jóvenes, dieron con respecto a sus progenitores, las pautas que siguieron para ello y el protagonismo que alcanzaron en tierras extremeñas; (2015), 387-404, una aproximación a los comportamientos de los jóvenes en el momento de contraer matrimonio en el mundo rural. También desde la Universidad de Valladolid hay que reseñar los trabajos de M. ${ }^{a}$ A. Sobaler Seco (2019), 15-44, en el que confronta el marco legal y la práctica cotidiana en los que se desenvuelven las desobediencias filiales y el consentimiento paterno en el contexto del matrimonio. Destaca su minucioso análisis de la legislación castellana y las disposiciones y decretos eclesiásticos. Por último, cabe mencionar el monográfico coordinado por el profesor A. IRIGOYEN LóPEZ (2019) en el que el cambio intergeneracional y la voluntad personal son los protagonistas.

3. Sin ánimo de ser exhaustivo, son relevantes para su consulta el volumen de F. García GonzÁlez (2008), F. Chacón y J. Bestard (2011) o el más recientemente publicado, J. F. Henarejos López y A. Irigoyen López (2017). 
rama posiblemente mucho más flexible a la luz de las nuevas fuentes y perspectivas. En este sentido nos preguntamos si los jóvenes que contraen matrimonio representan o no un papel pasivo en ese instante. Si hacen uso o no del derecho a expresar su voluntad personal, su decisión individual en las prácticas en torno al noviazgo y el acceso al matrimonio en el siglo XVIII. A través de tratados de familia, manuales de confesores, legislación de la época y pleitos -por disenso, divorcio, ruptura de contratos matrimoniales de los tribunales eclesiásticos de dos pequeñas ciudades, cabecera de diócesis: Ciudad Rodrigo y Sigüenza-, entre el siglo XVIII y principios del siglo XIX, analizamos el conflicto social y moral que deviene de la expresión de la voluntad personal de los jóvenes hijos de familia y la actuación de los poderes político y religioso en contra y a favor de esas pulsiones individualistas.

Frente a la importancia del honor y los preceptos de obediencia y la actitud paternalista y espíritu regalista que impregnan ciertas disposiciones legales -como la pragmática de 1776, o la reedición de manuales de familia del siglo XVI-, el consentimiento personal, que siempre estuvo vigente en la legislación canónica ${ }^{4}$, y la génesis conceptual de un nuevo individuo ilustrado ampararán la generalización de acciones individualistas, y transformarán los modos de vida sobre los que se expandirá la armadura ideológica, institucional y costumbres del liberalismo.

\section{LA JUVENTUD EN LA FAMILIA Y LA COMUNIDAD}

Entendida como edad del hombre, la juventud no existe fuera del ámbito de la familia. Una vez abandona el hogar a través del matrimonio, el joven deja de serlo y pasa a desempeñar funciones propias del pater familias; convertido en adulto, reproducirá este sistema, para el que ha sido adiestrado desde que abandona la adolescencia, con el fin de perpetuarlo. La juventud es interpretada, esencialmente, como una etapa formativa orientada a la edad adulta; durante su juventud, los miembros de la familia asumen funciones de aprendizaje, obligación y representación que no tienen los niños. A diferencia de éstos, no son sostenidos para preservar su supervivencia física, sino para garantizar la supervivencia material y social del grupo familiar.

4. En el ámbito religioso, la doctrina católica siempre sostuvo la libre elección de cónyuge como fundamento del matrimonio, otra cuestión es que esa expresión fuera forzada o no. En este sentido, es interesante analizar la doble postura de la Iglesia. 
El joven, por tanto, desarrolla sus últimos años de convivencia en el hogar bajo la tutela de sus padres. Cabe preguntarnos si progresivamente consciente de esta transitoriedad.

El modelo de la familia regulada ${ }^{5}$ es, básicamente, el molde con el que la juventud es interpretada por el pensamiento español durante la mayor parte de la Edad moderna y, significativamente durante la Ilustración, cuya naturaleza conservadora en España reviste características que tiñen de moralidad el pensamiento social a lo largo de toda la segunda mitad del siglo XVIII y los primeros compases del XIX. La necesidad de orden que respiran los textos impone aún entonces un paradigma social determinado por el honor que, tal como ocurre en los albores de la modernidad, impera en el centro de gravedad de las familias como una cualidad moral que afecta transversal y horizontalmente a todos sus componentes porque se proyecta directamente sobre la opinión, la estimación o la fama pública de la misma. La función de la juventud regulada es preservarlo.

\section{UNA DESOBEDIENCIA CRÍTICA}

Pero ser joven implica, como ahora, un momento de cambio personal vivido a veces críticamente: ante los ojos de la juventud se abre un escenario de posibilidades potencialmente peligroso para el orden social y para la moral establecidos, un escenario del que difícilmente pueden sustraerse por completo ninguno de sus actores.

Buena parte de la literatura política y moral a lo largo del siglo XVIII tiene por objeto mostrar precisamente los límites morales en los que debe mirarse el joven para desempeñar el papel que se espera socialmente de él. El ámbito en el que esos límites cobran sentido es el entorno familiar. No en vano, entendida la juventud como un momento de emergencia de la voluntad individual, la familia se convierte en el aval de las buenas costumbres y en el intermediario necesario entre el individuo y la comunidad, en un moderador que opera en diferentes niveles, primero como catalizador de los impulsos individualistas de los miembros que la componen a través de la educación, y después, si es necesario, como un instrumento de coerción -personificada en la figura del padre- sobre las actitudes rebeldes de los jóvenes, cuando el freno preventivo y racional del consejo familiar no ha dado resultado.

Gran parte de la originalidad del pensamiento ilustrado sobre la familia en España radica precisamente en el modo con el que afronta intelectual-

5. A. Arbiol (1805).

C Baetica. Estudios Historia Moderna y Contemporánea, 39, 2019, 171-187.

Facultad de Filosofía y Letras, Universidad de Málaga. Departamento de Historia Moderna y Contemporánea 
mente dicho proceso de cambio. A lo largo del siglo XVIII se afianza en él la figura del padre-educador, guía de sus hijos -casi siempre a partir del ejemplo de vida-, consciente de los límites de la violencia justa y modelo de comportamiento moderado y prudente. En el seno de las familias comienza a percibirse la posibilidad de aceptar cierto grado de disidencia entre los jóvenes vástagos, siempre que esa desobediencia no devenga en rebeldía, consintiendo por tanto un modelo de desobediencia crítica que nos pone en contacto con un ensanchamiento de los márgenes de libertad entre los jóvenes.

A lo largo de los siglos que componen la modernidad es palpable que la preocupación principal de las familias será erradicar o al menos controlar estos impulsos, fruto de la desobediencia irracional y origen de escándalos y de todo tipo de calamidades. Como la dimensión del problema excede con creces el ámbito familiar, instalándose en el corazón mismo de la república, en su ayuda opera buena parte del pensamiento moral y político, provisores de herramientas de refuerzo del control paternal y aliados fieles en el mantenimiento del orden establecido. Ejemplo de ello son las Pragmáticas de 1776 y 1803 o los numerosos tratados sobre la familia que se escribieron y reeditaron a lo largo del Siglo de las Luces: "Tres cosas principales deben los hijos a sus padres, que son el honor, la obediencia y el socorro competente para el remedio de sus necesidades" sentencia a principios del siglo XVIII uno de los manuales de mayor éxito ${ }^{6}$. Arbiol, cuya obra se reeditó más de una docena de veces entre 1705 y 1846, eleva la obediencia a eje central a partir del cual deben organizarse las relaciones familiares entre padres e hijos, en el mismo sentido con el que es utilizada desde el Renacimiento, es decir, como servidumbre o servicio a la casa. La novedad consistirá, como advertíamos anteriormente, en subrayar el reconocimiento de una autonomía crítica por parte del joven.

Sin duda, si admitimos una realidad histórica que apunta progresivamente a la implantación de un modelo social basado en el individualismo, esas "tres cosas principales" de las que nos habla Arbiol acarrean una serie inevitable de consecuencias. Una de ellas, quizás la más evidente,

6. A. Arbiol (1805), 476. Estas tres cosas las podemos concretar en la sujeción o subordinación del individuo a la autoridad de los padres a tres niveles: a nivel de las relaciones interpersonales, a nivel jurídico-político y a nivel moral y de los sentimientos. $\mathrm{O}$, en palabras de fray Luis de León, a la servidumbre entendida como ayuda o prestación de servicios vitalicia. Lo cual conecta con el sentido filosófico que el mundo romano otorgaba al ser joven; la juventud se traduce como aduviare, que designa la acción de ayudar, apoyar o sostener a alguien y del que se deriva el vocablo iuvenis, joven como indican A. Acevedo Tarazona y A. D. Correa Lugos (2016), 202. 
consiste en contemplar el proceso de transición que define a la juventud como una constante que se alarga en el tiempo, pues hace prevalecer los componentes básicos de la patria potestad sobre los hijos mientras los padres se mantengan con vida. Honor, obediencia y socorro deben protegerse como obligaciones filiales que se extienden más allá de la emancipación, en virtud de una autoridad de naturaleza política reconocida a los progenitores.

La reafirmación constante de estos principios elementales de adoctrinamiento social puede ser entendida, de otro modo, como una forma de confrontación de las familias y comunidades de Antiguo Régimen ante la emergencia de actitudes individualistas entre los jóvenes, pero es posible que su existencia deba rastrearse en escenarios que, aunque no son exclusivos de la juventud, les son propios.

\section{ESCENARIOS DE LIBERTAD: LAS RELACIONES PRENUPCIALES}

A pesar de admitir que la juventud no existe al margen de la familia, no es menos cierto que los procesos de sociabilidad que les son propios se desarrollan, en parte, al margen de la familia. Naturalmente, estos escenarios no son los mismos entre unos lugares y otros. Las pautas culturales dominantes en el mundo rural, por ejemplo, se construyen sobre bases netamente distintas a las que rigen entre los jóvenes habitantes de las ciudades. Existen diferencias geográficas evidentes entre unos y otros, rasgos propios y límites concretos dibujados con precisión. Sin embargo, sí existe cierto patrón común cuando observamos los diferentes modos con los que se comportan los jóvenes en función de su origen social y el lugar que sus respectivas familias ocupan en el contexto de la comunidad de referencia.

Esta reflexión queda bien reflejada en las fuentes documentales. En 1734 se interpone un pleito matrimonial ante el tribunal eclesiástico de la pequeña ciudad diocesana de Sigüenza ${ }^{7}$. La razón es la más común entre los asuntos vistos por los jueces eclesiásticos, la ruptura unilateral de la palabra de matrimonio dada. Por suerte, en él se nos describen con mucho detalle dos espacios de ocio distintos frecuentados por los jóvenes sigüentinos: por una parte, los espacios festivos domésticos, lugar de celebración de bailes nocturnos que organizan los vecinos, decididos a convertir ocasionalmente sus casas, templos de moral, en un lugar de diversión pública. En ellos

7. Se trata de un pleito por palabra de matrimonio incumplida, estupro y reconocimiento de la prole que Librada Letón interpone contra Juan de Juana, ambos solteros de Sigüenza. Archivo Diocesano de Sigüenza (ADS), Tribunal Eclesiástico, 1734, s. f. 
participan gentes de toda clase, atraídos por el bullicio y la música, mozos y jóvenes solteras que se divierten al son de las guitarras con canciones típicas del país. Bailan indistintamente unos con otros, en compañía de los padres, cuya presencia garantiza cierta supervisión de estos encuentros o por lo menos proporciona cierto halo de normalidad.

Por otra parte, encontramos espacios de ocio cotidiano compartidos por hombres y mujeres de cualquier estado y edad, padres e hijos, sentados a las puertas de las casas, conversando las noches de verano. Esta costumbre, todavía hoy vigente en buena parte del mundo rural español, era habitual también en las calles de Sigüenza, por lo que, "aunque tengan risas y algunas algazaras, no se atribuye a deshonestidad aunque allí concurran doncellas" y mozos que se "chanceaban" con las mujeres indistintamente, "conforme al estilo que solían practicar". No es del todo improbable que algunos de los matrimonios concertados posteriormente tuviesen en esos momentos de ocio compartido su primera sugerencia.

¿Cuáles son los márgenes de acción de los jóvenes en este contexto relativamente vigilado? En el mundo del ocio, el control de los hijos es, sin duda, una preocupación constante de los padres; especialmente el de las hijas por su trascendental papel en el sostenimiento de la honra familiar. Las mozas honestas no salen de casa si no es con permiso de los padres y siempre sin apartarse de la misma calle en la que habitan ${ }^{8}$. Así pues, su marco de actuación queda reducido a una suerte de espacio doméstico ampliado, compuesto esencialmente por lugares frecuentados a diario. Las casas de los vecinos, los huertos próximos, el lavadero o la tahona son los espacios de referencia de una vida honesta. Sin embargo, es evidente que los jóvenes encontraban intersticios en ese espacio controlado para tratarse a solas o en compañía de otros, con los que comparten códigos de comportamiento. En el mundo rural, además, la participación activa de las mujeres en la economía familiar propicia escenarios alternativos de convivencia, regulados por el calendario agrario 9 . Así, en el caso de las mujeres, vemos que tienen márgenes de acción más amplios.

8. Lo cual nos remite a la obra de L. Vives, De Institutione feminae christianae, cuando habla de cómo la virgen debe salir de casa, en las ocasiones que sea imposible evitarlo, embozada, sin cruzar palabra...

9. P. SAAVEDRA Fernández (2001), 115 y ss. En este trabajo se nos habla de otros escenarios de los que hemos evitado hablar aquí, como son las veladas invernales, los mercados, las ferias, que motivan la ausencia de los padres del hogar, las romerías, las reuniones para merendar chocolate (en las ciudades es cada vez más notable la presencia de tratantes de dulces o chocolates; en Trujillo por ejemplo, en el año 1761, encontramos a dos tratantes de chocolate y seis de dulces), pero también reuniones clandestinas para echar partidas de naipes... 
En 1760 se inicia en el tribunal eclesiástico de Sigüenza un nuevo pleito matrimonial. Difiere del anterior en que los protagonistas no son naturales de la ciudad, sino de la pequeña población de Turmiel, donde el trato entre ellos es más asiduo debido, según el procurador que lleva la causa, a lo que califica con el expresivo apóstrofe de "rusticidad"10. Al margen de la opinión que transmite el abogado de la defensa con este apelativo, sus palabras dejan entrever una forma de transgresión impropia en otros escenarios más civilizados. Es decir, las gentes del mundo rural se tratan sin las limitaciones a las que está sometida la rígida moral social de la capital diocesana. No solo aprovechan festividades y momentos de ocio, sino que al tiempo que se llevaban a cabo las tareas agrícolas existen momentos de diversión alternativos ${ }^{11}$ : comparten el cálido suelo de las eras por la noche durante la trilla, comparten lumbre para calentarse en invierno mientras guardan el ganado, juntos recogen hierbas, escobas, setas o leña cortada.

Los protagonistas de este pleito participan habitualmente de este modo de vida. En realidad, la fuente nos cuenta una historia de amor entre dos jóvenes: Juan y María. Su aventura amorosa comienza en un caluroso mes de agosto, mientras ambos protagonistas acarreaban leña, acompañados de otros mozos. Suponemos que hubo algún tipo de contacto previo entre ambos, porque Juan declaró su amor a María y le preguntó si quería casarse con él. Su respuesta fue inmediatamente positiva, sin que las familias tuvieran participación ni conocimiento del compromiso, con lo cual sus encuentros y demostraciones de afecto tenían lugar a escondidas. Más difícil de esconder fue, pasado el tiempo y estrechado los lazos entre ellos, el embarazo que comenzaba a ser visible en María y que pronto despertó la indignación y la curiosidad de sus convecinos. Para explicar lo sucedido sin menoscabar más aún la ya dañada reputación de su cliente, el abogado de la defensa tuvo que describir estos encuentros como el resultado de increíbles casualidades más o menos azarosas. Por ejemplo, ambos se encuentran en la dehesa mientras María, en compañía de otros mozos, iba a guardar las ovejas de su padre. Juan aprovechó para emplazarla a una cita a escondidas al día siguiente en los campos donde él araba. Al atardecer se encontraron allí, con la excusa de trasladar el ganado de su padre a un predio que poseía en las cercanías, donde se conocieron carnalmente aquella misma tarde. Más difícil de describir como casuales fueron otras ocasiones ocurridas

10. ADS, Tribunal Eclesiástico, 1760 fol. 29. Pleito de María López Ibáñez, de 23 años, contra Juan Marco Sanz, de 25, por incumplimiento de esponsales y daños.

11. P. SaAvedra Fernández (2001), 116-117. 
a diversas horas del día y en distintos lugares -el sitio de las Trillas, en el Carrascalejo, en el sitio de los Vallejos, en la Machacona-, todo ello incluso con la complicidad de otros amigos o conocidos de la pareja, sin faltar algunos familiares cómplices, entre los que descubrimos a su propia madre ocultando la relación al marido, desconocedor de los retozos y juegos con los que su hija entretenía las duras labores del campo. En otra ocasión será su prima, de la misma edad, con la que María iba a recoger hierbas y que, oportunamente, al encontrarse ambas con Juan, les dejó solos con el pretexto de ir a dar una vuelta a unos lazos que había puesto para coger perdices. Momento que no es desaprovechado por nuestros protagonistas.

Sin abundar en más detalles, por muy habitual que fuesen este tipo de comportamientos entre los jóvenes del lugar se desarrollaban formalmente al margen de la voluntad de las familias que ejerce un férreo control sobre las expectativas de matrimonio de sus hijos. Por el contrario, tampoco podemos negar el ejercicio de expresión de la voluntad personal que encierra este documento, porque las relaciones prenupciales se establecen entre los componentes de un grupo social, definido por la edad, conocido entre sí, sin la participación directa de las rígidas estrategias familiares. Esta es la forma que adopta la rebeldía más común entre los jóvenes modernos, la que proviene del sentimiento y es fruto de las expresiones personales de afecto. Abunda en esta realidad un testimonio recogido en Hinojosa de Duero un año antes.

El 14 de mayo de 1775, María Gallego, natural de Hinojosa, menor de edad, soltera y honesta, interpuso un pleito matrimonial por incumplimiento de esponsales contra Francisco Sánchez Amador, de su misma vecindad y condición, ante el tribunal eclesiástico de Ciudad Rodrigo ${ }^{12}$. Este pleito destaca por la aparición del término "enamorados" para hacer referencia a parejas de jóvenes que se eligen sentimental y particularmente entre ellos, sin injerencia de las familias.

La estrategia de la acusación deseaba dejar bien claro que la honestidad de María no estaba en entredicho y por tanto carecía de motivos justificados para reclamar que se cumpliese con una palabra de matrimonio dicha en un contexto de relaciones no formales. Para ello indagan sobre tales prácticas con la clara voluntad de separar los rituales del matrimonio concertado, de los modos y lugares con los que los jóvenes de ambos sexos se tratan en sus momentos de ocio compartido. Las preguntas de la $4^{\mathrm{a}}$ a la $7^{\mathrm{a}}$ del segundo interrogatorio se redactaron con ese fin: 
4. Si saben (...) tratándose y comunicándose con honesta confianza es regular como cosa tan común y proporcionada en mozos que estos, llevados de la juvenil inquietud, "jugueteasen” y retozasen (...) sin ánimo alguno de cometer torpeza ni acto executivo contra la honestidad y honor (...) y por solo entretenimiento (...).

5. Si saben que en la dicha villa y otras de su contorno, es estilo usado entre mozos solteros decir muchos de ellos, o los más, que tienen sus enamoradas, las que festejan, visitan y cortejan en sus proporcionados modos, viéndose y hablándose en sus ocasiones sin más fin que manifestarse una buena afición y bienquerencia, y sin que por esto, ni que algunas veces como suele jugueteen, se entienda estar apalabrados, ni por ello significar ánimo de obligación o promesa a casarse, antes bien, en esto suelen variar los más y se dice por vulgar proverbio entre ellos que de los enamorados, son los menos los casados, dando a entender que regularmente son pocos o los menos de estos los que se casan uno con otro (...).

6. Si sabe (...) que por tales entretenimientos y enamoramientos, las mozas que se dice ser enamoradas de este o de otro mozo y tratándose algún tiempo, no por esto pierden su estimación y honesta opinión, ni dejan de casarse honrosa y sanamente con la persona que se le proporciona o sus padres le acomodan, conforme a su calidad y circunstancias, y que, si alguna vez se dispone, casen entre sí los dos que se dicen enamorados, se trata bien entre estos, bien por medio de sus padres o parientes, seria y formalmente, dándose expresa fe y palabra, que deliberadamente demuestre y signifique ánimo y prometimiento con que se obliguen a casar el uno con el otro y siempre que no llega a estos términos serios no se entiende ni presume en ellos otra cosa que un afectuoso y juvenil pasatiempo.

7. Si saben que en el tiempo que un mozo trata y comunica con afición alguna moza en la forma susodicha y con el expresado título que dicen de enamorados, es regular y frecuente en dicha villa que estos se den y pidan el uno al otro o se tomen el uno al otro con llaneza algunas cositas leves de que estos usan, como cordón, cinta o sortija, sin que por ello se entienda ser su ánimo obligarse a casar y sí solo una fineza significativa de su cariño ${ }^{13}$.

Y resulta que sí. Una testigo, María Santos Naranjo, mujer de Juan Bajo Arroyo, de 56 años, responde que es costumbre que, en diversas fiestas, los mozos les pongan a sus enamoradas en ventanas y puertas frutas, lechugas y cosas del tiempo, y cantarles por las noches sus cantares "conforme el estilo del país", sin más motivo que el de expresar su cariño sin ninguna obligación. Más adelante, uno de los procuradores denomina estas relaciones

13. ADCR, Tribunal Eclesiástico, 1775, fol. s.f. 
como "amores juguetones", fruto, nuevamente, de la "rústica llaneza", que no comportan ofensa para la honestidad de las mujeres ni obligación de casar para los hombres. Es más, una muchacha de 26 años, María Lorenzo Gamito, mujer de Benito Romo, dice que "sucede quasi comúnmente casarse con otras que no han corrido con el título de enamorada". Y a la propia María Gallego se le recuerda que, en una ocasión, ella misma dijo en presencia de testigos que "para enamorar, el que mejor parezca y para casar, el que convenga". Declaraciones que nos dan a entender el peso que aún tienen las familias y la comunidad para imponer su voluntad por encima de la elección personal de los hijos, al menos formalmente.

Las declaraciones de los testigos presentes en Hinojosa de Duero nos ayudan a plantear la idea ya expuesta en otros trabajos de la superposición habitual de tres niveles de consentimiento ${ }^{14}$ que operan alrededor de las prácticas del mercado matrimonial. El consentimiento individual, voluntariamente expresado por los futuros novios se consagró en los cánones eclesiásticos como el principal de ellos. Un segundo nivel de acuerdo implica el consentimiento de la familia, que vela por las buenas costumbres y el tercero es el que atañe a la comunidad, que aprueba o no el enlace a través de la opinión pública. Sin embargo, el peso cada vez mayor del consentimiento individual como base para la legitimación sacramental y civil del matrimonio, y la normalización de estas relaciones no formales en la comunidad van a ser el punto de partida para un proceso de individualización en el interior de la familia. Es decir, el primitivo pensamiento de libertad de "poder elegir" y la voluntad del joven en consentir o no racionalmente, con criterio, serán la base de un individualismo primitivo ${ }^{15}$ nacido en la familia moderna, que será promovido, en ciertos ámbitos, por los poderes religioso y político y, al mismo tiempo, condenado y reprendido por esos mismos poderes.

\section{CONCLUSIONES}

La juventud existe en tanto que es etapa de formación del individuo dentro de la familia, con el objetivo de la reproducción y perpetuación social del grupo. En este sentido, durante la mayor parte de la Edad Moderna la piedra clave sobre la que pivotan las relaciones paterno-filiales en el pen-

14. J. P. Blanco Carrasco (2016), 127; (2019a), 330; (2019b), 53.

15. J. P. Blanco Carrasco (2016), 109; E. Paoletti Ávila y J. P. Blanco Carrasco (2018), 404-405. 
samiento español es la obediencia. El modelo de la familia regulada ${ }^{16}$ se verá reforzado desde la Ilustración, cuya necesidad de orden impregna de moralidad el pensamiento social de toda la segunda mitad del siglo XVIII y los primeros compases del XIX. Sin embargo, el pensamiento ilustrado sobre la familia en España comienza a abrir márgenes de libertad entre los jóvenes al consentir un modelo de desobediencia crítica.

Los jóvenes desarrollan esas desobediencias aprovechando procesos de sociabilidad ajenos a la familia, utilizando diferentes espacios de encuentro y reunión entre ellos, rompiendo, en ocasiones, el férreo control que ejercen las familias, sobre todo en materia de matrimonio. Lo hemos dicho más arriba, la forma más común que adopta la rebeldía entre los jóvenes modernos es la que proviene del sentimiento y es fruto de las expresiones personales de afecto. En los ejemplos que hemos podido analizar a través de los pleitos matrimoniales quedan reflejados ese ejercicio de la voluntad personal en las relaciones prenupciales, unas veces diluido y disimulado en el discurso de la época en torno a la doncella honesta. Pero es patente que, independientemente de su éxito posterior, los jóvenes son protagonistas de sus relaciones prenupciales, eligiéndose entre sí, sin la participación directa en un primer momento de las rígidas estrategias familiares. La novedad radica en la progresiva pérdida de capacidad coercitiva de las estrategias familiares, el progresivo repudio del matrimonio concertado como un atentado a la voluntad de elección del cónyuge.

Por supuesto, estas voluntades entran en conflicto con el orden del sistema familiar moderno e irá agravándose a medida que las familias pierdan progresivamente autoridad frente a la importancia del consentimiento personal en lo religioso y lo legal, y una nueva forma de entender al individuo desde el ideario ilustrado ${ }^{17}$. Frente a planteamientos contradictorios: por una parte importancia de la elección personal, de un individuo moralmente emancipado y por el otro el reforzamiento del control parental y la renovación de una moralidad que reitera unos principios básicos desde el siglo XVI, lo cierto es que el consentimiento se va constituyendo en pieza clave en el sistema matrimonial moderno. Esta voluntad personal se va cargando de sentimiento, amparado por la progresiva liberalización de las relaciones dentro de la comunidad, entendidas de una manera más libres, individualistas y sentimentales. Este proceso en España se inició, probablemente, en el mundo urbano, desde

17. E. Paoletti Ávila (2019), 356. 
donde pasaría al mundo rural, a medida que va calando el ideal ilustrado de la libertad personal ${ }^{18}$.

\section{BIBLIOGRAFÍA}

Acevedo Tarazona, Álvaro y Correa Lugos, Andrés David (2016), “Jóvenes: historia glocal de un concepto en evolución", Katharsis, 22, pp. 197-220.

Alba, Víctor (1975), Historia social de la juventud, Plaza \& Janes, Barcelona.

Arbiol, Antonio (1805), La familia regulada con doctrina de la Sagrada Escritura y Santos Padres de la Iglesia Católica, para que todos los que regularmente componen una casa seglar, a fin de que cada uno en su estado y en su grado sirva a Dios nuestro Señor con toda perfección y salve su alma, Madrid.

Blanco Carrasco, José Pablo (2016), "Disensos. Conflictos de la patria potestad en la España rural moderna", Studia Histórica. Historia Moderna, 38, 2, pp. 107-135.

Blanco Carrasco, José Pablo (2019a), "Notas sobre la desobediencia intergeneracional durante los últimos compases de la España Moderna", Tiempos Modernos. Revista electrónica de Historia Moderna, 9, 38, pp. 323-344.

18. J. P. Blanco Carrasco (2019a), 342. J. I. Israel (2012), 87, apunta que los principales semilleros de las ideas ilustradas radicales entre 1650 y 1750 fueron las ciudades, las principales, orientadas a la producción y el comercio internacional, con altísimos niveles de migración y centros de gobierno. Estas ciudades son un entorno de discusión y de relativa libertad. La aparición en estas ciudades de foros de opinión pública, que estaban fuera del dominio de las cortes principescas, de la magistratura, de la Iglesia o de los parlamentos -que el autor señala como publicaciones periódicas eruditas, las bibliotecas "universales", los clubes literarios, los diccionarios y enciclopedias, revistas para caballeros, casas de té y café o, incluso, las logias masónicas-, se conjugan con la excepcional fluidez en las relaciones sociales y movimientos entre estratos sociales que da lugar la gran ciudad. Es esta unión la que propicia la difusión de ideas, no solo en el ámbito urbano, sino también en el mundo rural. Aristócratas rurales en contacto con la corte, salones de conversación, el comercio manejado por arrieros, personas del mundo rural que acceden a puestos de servicio en ciudades y que posteriormente retornan a su núcleo rural de origen, oficios liberales que conllevan una alta movilidad, etc. todos estos ejemplos actuaron como vectores de difusión de noticias, situaciones vividas en la ciudad, modas... y pensamiento. El mundo rural no vive de espaldas a la realidad, en una burbuja, o en una realidad paralela. Los pueblos no participan de la misma forma que el mundo urbano, pero hay una difusión segura. Es relativamente fácil de demostrar a través de la cultura material. M. García Fernández (2004), 120. Lo que sí es cierto es que la velocidad del cambio en las ciudades puede percibirse documentalmente mientas que en el mundo rural nuestras herramientas solo nos permiten observar lentos cambios en el mundo de las mentalidades. 
Blanco Carrasco, José Pablo (2019b), "Desobediencias domésticas. Los jóvenes ante el modelo de autoridad familiar moderno", en J. P. Blanco CARrasco, M. García Fernández y F. Olival (coords.), Jóvenes y juventud en los espacios ibéricos durante el Antiguo Régimen. Vidas en construcción, CIDHEUS- Universidade de Évora, Edições Colibrí, Lisboa, pp. 45-72.

Blanco Carrasco, José Pablo, García Fernández, Máximo y Olival, Fernanda (coords.) (2019), Jóvenes y juventud en los espacios ibéricos durante el Antiguo Régimen. Vidas en construcción, CIDEHUS-Universidade de Évora, Edições Colibrí, Lisboa.

Chacón Jiménez, Francisco y Bestard, Joan (dirs.) (2011), Familias; Historia de la sociedad española (del final de la Edad Media a nuestros días), Cátedra, Madrid.

García Fernández, Máximo (2014), “Tejidos con 'denominación de origen extranjera’ en el vestido castellano. 1500-1860”, Estudios Humanísticos. Historia, 3, pp. 115-145.

García Fernández, Máximo (2019), Los caminos de la juventud en la Castilla Moderna. Menores, huérfanos y tutores, Sílex, Madrid.

García GonzÁlez, Francisco (ed.) (2008), Historia de la familia en la península ibérica, balance regional y perspectivas: homenaje a Peter Laslett, Universidad de Castilla la Mancha, Albacete.

Henarejos López, Juan Francisco e Irigoyen López, Antonio (eds.) (2017), Escenarios de familia: trayectorias, estrategias y pautas culturales, siglos $X V I-X X$, Universidad, Murcia.

Irigoyen López, Antonio (coord.) (2019), Dossier Hijos y padres en la España del Antiguo Régimen: individualismo y estrategias familiares, Tiempos Modernos. Revista electrónica de Historia Moderna, 9, 38.

IsRAEL, Jonatahn I. (2012), La Ilustración radical. La filosofía y la construcción de la modernidad, 1650-1750, Fondo de Cultura Económica, México.

Levi, Giovanni y Schmitt, Jean-Claude (cords.) (1996), Historia de los jóvenes, tomos I y II. Santillana Taurus, Madrid.

Mitterauer, Michael (1992), A History of Youth (Family, Sexuality, and Social Relations Past Times), Blackwell Pub., Oxford.

Paoletti Ávila, Elena (2015), “Los primeros pasos de la madurez. Juventud y matrimonio en el interior peninsular a finales del siglo XVIII", Norba. Revista de Historia, 27-28, pp. 387-404.

- (2019), "Cambio intergeneracional: ascenso económico y social de emigrantes en la Extremadura de finales del Antiguo Régimen", Tiempos Modernos. Revista electrónica de Historia Moderna, 9, 38, pp. 345-361.

Paoletti Ávila, Elena y Blanco Carrasco, José Pablo (2018), “Calla y otorga. Obediencias y desobediencias en el sistema matrimonial de Antiguo Régimen. Un ejemplo rural hispano”, en J. S. Amelang; F. A. Robres; R. Benítez Sánchez-Blanco; R. Franch Benavent y M. Galante (eds.), Palacios, plazas, patíbulos: la sociedad española moderna entre el cambio y las resistencias, Tirant lo Blanch, Valencia, pp. 393-406. 
De los enamorados, son los menos los casados. La expresión de la...

SaAvedra Fernández, Pegerto (2001), “Ocio y vida cotidiana en la España rural del siglo XVIII”, en L. A. Ribot García y L. DE Rosa (dir.), Trabajo y ocio en la época moderna, Actas, Madrid, p. 111-138.

Souto Kustrín, Sandra (2007a), "Juventud, Teoría e Historia: la Formación de un Sujeto Social y de un Objeto de Análisis", HAOL, 13, pp. 171-192.

— (2007b), "Introducción: juventud e Historia”, Hispania, LXVII, 225, pp. 11-20. 